The brain tumor in the nontreated sister is stable in size, but she has developed facial angiofibroma and renal AMLs. Early mTOR inhibition in TSC patients may prevent the development of TSC lesions and alter the natural history of the disease. (Kotulska K, Bortkowska J, Jozwiak S. Possible prevention of tuberous sclerosis complex lesions. Pediatrics 2013 Jul;132(1):e239-42). (Response: Dr Kotulska. k.kolulska@ezd.pl).

COMMENT. The approach to the management of tuberous sclerosis complex (TSC) has become more demanding because novel TSC-specific treatments are now available, and indications for intervention vary with age and organ system. Periodic MR imaging is advised every 1-3 years to exclude development of subependymal giant cell astrocytoma and need for treatment with everolimus, negating the need for invasive surgery. Routine EEG in asymptomatic TSC infants for the first year or two of life is increasingly accepted, with treatment initiation of vigabatrin if indicated at the earliest sign of developing hypsarrhythmia. (Krueger DA. Curr Treat Options Neurol 2013 July 13).

\title{
ATTENTION DEFICIT HYPERACTIVITY DISORDER AND EEG
}

\section{METHYLPHENIDATE-INDUCED SEIZURE, ADHD AND ABNORMAL EEG}

Investigators from Harvard Medical School, Boston, present the case of a 6-yearold girl with ADHD taking valproic acid for behavioral problems who had a generalized tonic-clonic convulsion shortly after a first dose of methylphenidate. She was known to have staring spells and an abnormal EEG with left centroparietal spikes but no history of electrographic seizures. A repeat EEG demonstrated continuous spike and slow wave during sleep. CSWS in sleep may be a risk factor for methylphenidate-induced seizure. (Sheen VL, Shankar M, Marin-Valencia I, Bridgemohan CH, Torres AR. Methylphenidate and continuous spike and wave during sleep in a child with attention deficit hyperactivity disorder. Pediatr Neurol 2013 Jul;49(1):54-7). (Response: Dr Torres. E-mail: Alcy.torres@childrens.harvard.edu).

COMMENT. This article corroborates previous reports of the utility of the EEG in children with ADHD and the increased risk of methylphenidate-induced seizures in patients with EEG centrotemporal (rolandic) spikes (Hemmer SA, et al. Pediatr Neurol 2001 Feb;24(2):99-102) and CSWS in sleep. Sleep deprivation in preparation for a sleep EEG is essential to exclude epileptiform abnormalities; one quarter of nonepileptic children with ADHD have epileptiform discharges in the sleep-deprived EEG compared to only $7 \%$ in awake only EEG, and slightly more than half discharges are focal (Millichap JJ et al. J Child Neurol 2011 Jan;26(1):6-11). 